\title{
The Application of Ultrasonic in Degumming for Hemp
}

\author{
Yulu Guo \\ School of textile, Tianjin Polytechnic University \\ 63 Cheng Lin Street, Tianjin 300160, China \\ E-mail: guoyulu0000@163.com \\ Shulin Zhao \\ School of textile, Tianjin Polytechnic University \\ 63 Cheng Lin Street, Tianjin 300160, China \\ E-mail: zhaoshulin@tjpu.edu.cn
}

\begin{abstract}
This paper introduces the progress of ultrasonic degumming study, and studies the major parameter of ultrasonic degumming by experiments and the principle ultrasonic degumming for china-hemp.

Keywords: Hemp, Degumming, Ultrasonic

\section{Introduction}

Degumming plays an important role in the process of the formation of the fiber of the hemp, and has a great effect on the properties of fiber and quality of hemp yarn and so on. The traditional degumming process of hemp includes mechanical, chemical or enzyme methods. the mechanical method of degumming depends on the weather leading to the unstable properties of hemp fiber; the chemical method of degumming needs a lot of water and chemicals which are not good to the environment; enzyme degumming will encounter difficulties in the application of commercialization due to the difference in the reactivity of enzyme. So it is necessary to find a route which can reduces pollution, lowers energy consumption, has high ratio of performance to cost price, and can significantly improve the fiber fineness, cleanliness, reduce the 'granulites'. It is good to make it industrial as soon as possible.
\end{abstract}

\section{Experiment}

Major study of hemp ultrasonic degumming is the ultrasonic frequency, power density, processing capacity and configured base fluid, along with textiles principle of ultrasonic degumming. That is the frequency of ultrasonic degumming experiment, sound intensity, sound field distribution, temperature, media, etc, five major parameters.

At present, the application of ultrasonic frequency mainly falls in the context of $20 \mathrm{KHz}$ to $50 \mathrm{KHz}$. The higher the frequency is, the higher the cavitations' threshold is, and the larger the umber of cavitations bubble is, but the cavitations intensity is very low when it collapses, and it is usually applied to the subject in which the removed material has weak bonding with the body object. When the frequency is lower, cavitations intensity is high, the impact is strong, and so it is often applied to the subject in which the removed material has strong bonding with the body object. The lowest sound intensity which can transfer liquid to air is called cavitations threshold, above it ,the louder sound is, the stronger cavitations is, and the choice of sound intensity has a good relationship to the character of processing object. To make the cleanness uniform, Electro-acoustic sound field should be a mixed field rather than standing-wave field, the design of sound field and selection of band have relationship to the geometry of ultrasound groove. When the main parameters above are determined, ultrasound result is mainly related to temperature and media, increasing temperature will cause both surface tension and viscous coefficient of process object to reduce, hence cavitations threshold low so that the air is easily produced; but with the temperature increasing, higher vapor pressure will lower the cavitations intensity. Therefore we should choose a reasonable optimal temperature. In the ultrasonic testing of hemp, the ratio of media when choosing temperature should also be considered so as to maximize auxiliary effectiveness in chemical.

Experimental technology is as Figure 1

Result as Table 1 3 
We can see in the different degree of treatment from Figure 2, gum changes on the surface of hemp.

Experimental results show that the better power density is $0.45 \mathrm{~W} / \mathrm{cm}^{2}$. Therefore, the effect of ultrasonic degumming does not keep proportional to the density of power, degumming using small power with long time could not get good result, while power increases to certain value the effect will be seen immediately. But larger power will destroy the fiber, low strength of fiber; at the same time, the radius of bubble also increases so as to low the number of bubble entering into the gap of hole, as a result, intension of degumming will relatively be reduced; when the density of power is so larger that the number of produced bubble increases dramatically forming a screen, which hindered the acoustic radiation throughout the cylinder, so that effect impacted on the areas away from the sound source is weakened, and make degumming uneven.

\section{Principle}

When a certain sound intensity of ultrasonic acts on the liquid, it would produce a tearing force in a certain area, and the cavitations bubble under the action of force produce and grow, but they were immediately extruded to collapse because of the compression force. With the collapse of the cavitations bubble part high-pressure and high-temperature effects are produced, which is called effect of cavitations. It is this effect that makes ultrasonic degumming possible.

From the results of experiment, the optimum process of treatment of degumming is temperature of $55^{\circ} \mathrm{C}$, the concentration of sodium hydroxide of $1.5 \%$, the density of ultrasonic of $0.45 \mathrm{~W} / \mathrm{cm}^{2}$ and the frequency of 28 KHz.

Ultrasonic degumming is actually strip process of continuous explosion. As shown in Figure 3, on the surface of hemp, there are many cracks and holes, and cavitations bubble under the effect of the sound field enter into these cracks and holes, then they burst, the impact produced makes the gap between gum and fibers large, under the continuous impact of the cavitations bubble, the gum is eventually peeled off, shedding gum was again detracted by shock waves from cavitations. At the same time, rupture of bubble brings high-temperature in partial area to contribute to reaction of solution of sodium hydroxide to colloid, and reduces the force required to peel off gum.

Therefore, an appropriate bubble radius and the appropriate production of bubble and how to achieve resonance will seriously affect the effectiveness of hemp degumming. In general, radius distribution of cavitations bubble is consistent with Gaussian curve, as shown in Figure 4. When the values of the cavitations bubble mostly locate in the top of Gaussian curve, it will get optimal ultrasound results.

In the adiabatic state, mobility equation of bubble is written:

$$
R \frac{d^{2} R}{d t^{2}}+\frac{3}{2}\left(\frac{d R}{d t}\right)^{2}=\frac{1}{\rho}\left[\left(P_{o}-P_{v}+\frac{2 \sigma}{R_{o}}\right)\left(\frac{R_{o}}{R}\right)^{3 \gamma}-P_{o}-P_{V}-P_{A}-\frac{2 \sigma}{R}\right]
$$

Then minimum and maximum of critical radius of cavitations bubble are respectively as follow:

$$
\begin{gathered}
\mathrm{f}=\frac{1}{2 \pi R} \sqrt{\frac{3 \gamma}{\rho}\left(\mathrm{P}_{\mathrm{o}}+\frac{2 \sigma}{R}\right)} \\
R_{\min }{ }^{3}+\frac{2 \sigma}{P_{O}-P_{V}} R_{\min }{ }^{2}-\frac{32}{27} \frac{\sigma^{3}}{\left(\mathrm{P}_{A}+\mathrm{P}_{V}-\mathrm{P}_{O}\right)^{2}\left(P_{O}-P_{V}\right)}=0
\end{gathered}
$$

* $\mathrm{f}$ - cavitations bubble resonant frequency; $(\mathrm{Hz})$

$\gamma$-ratio of specific;

Po-hydrostatic pressure; $(\mathrm{Pa})$

$\sigma$-surface tension coefficient ; $(\mathrm{N} / \mathrm{m})$

$\mathrm{R}$ - cavitations bubble initial radius; $(\mathrm{m})$

$\mathrm{R}_{\min }-$ minimum radius; $(\mathrm{m})$

$\mathrm{P}_{\mathrm{V}}$-vapor pressure; $(\mathrm{Pa})$

$\mathrm{P}_{\mathrm{A}}$ - sound pressure; $(\mathrm{Pa})$

Cavitations bubbles under the action of sound quiver, but not necessarily broke. Only if the frequency of sound wave is lower than that resonant frequency of the bubble, the bubble broken. Cracks and holes on the surface of 
the hemp bast fiber are mostly from a few $\mu \mathrm{m}$ to hundreds $\mu \mathrm{m}$ level, under the optimal parameter, the bubble radius in the degumming trial of hemp ranges from $2.35 \mu \mathrm{m} \sim 115 \mu \mathrm{m}$, which basically meets the requirements of the degumming cavitations radius.

\section{Epilogue}

So far the essence of ultrasonic cavitations still is an unsolved problem, because power ultrasonic is mostly applied to cleaning rigid materials, and the studies in the field of materials with nature of absorbing sound strongly is very poor, so in this paper carried out primary exploration on the basis of this project about degumming of hemp.

\section{References}

Bao Shanhui, Chen Ling. (2004). The Principle of Ultrasonic Cleaning. Journal of Further Education of Shanxi Normal University, 2, 107-109

Becchetti FD. (2002). Evidence for Nuclear Reactions in Imploding Bubbles. Science, , 295 ,1850

Chen Sizhong. (2004). Ultrasonic Cleaning Technology and its Development. Cleaning technology, 2, 7-12

Jian Guohua. (2003). The Application of Ultrasonic in Preprocessor of Hemp Degumming. Plant fiber and products, 2, 83-85

Yang Yingxian. (2006). Research on Apocynum Venetum Degumming with Ultrasonic. Qing Dao University Master's Degree Paper, 20-30

Yin XG, Hua JK. (2003). The Study on Explosion of Hemp Fibers. J Cellulose Sci Technol, 11, 1-7

Table 1 . The content of residual gum in different power density

\begin{tabular}{|c|c|c|c|c|c|}
\hline $\begin{array}{c}\text { Power density } \\
\mathbf{W} / \mathbf{c m}^{2}\end{array}$ & 0.35 & 0.40 & 0.45 & 0.50 & 0.60 \\
\hline $\begin{array}{c}\text { residual gum } \\
\%\end{array}$ & 9.72 & 8.14 & 7.93 & 7.94 & 7.8 .03 \\
\hline
\end{tabular}

*temperature $55^{\circ} \mathrm{C}, \mathrm{NaoH} 1.5 \%$

Table 2. The content of residual gum in different temperature

\begin{tabular}{|c|c|c|c|c|}
\hline $\begin{array}{c}\text { Temperature } \\
{ }^{\circ} \mathrm{C}\end{array}$ & 45 & 50 & 55 & 60 \\
\hline $\begin{array}{c}\text { residual gum } \\
\%\end{array}$ & 9.02 & 7.95 & 7.92 & 8.01 \\
\hline
\end{tabular}

*power density $0.45 \mathrm{~W} / \mathrm{cm}^{2}, \mathrm{NaoH} 1.5 \%$

Table 3 . The content of residual gum in different consistency

\begin{tabular}{|c|c|c|c|c|c|}
\hline $\begin{array}{c}\text { Consistency } \\
\%\end{array}$ & 0 & 1.0 & 1.5 & 2.0 & 3.0 \\
\hline $\begin{array}{c}\text { residual gum } \\
\%\end{array}$ & 12.5 & 7.95 & 7.94 & 8.01 & 9.15 \\
\hline
\end{tabular}

* Power density $0.45 \mathrm{~W} / \mathrm{cm} 2$, temperature $55^{\circ} \mathrm{C}$ 


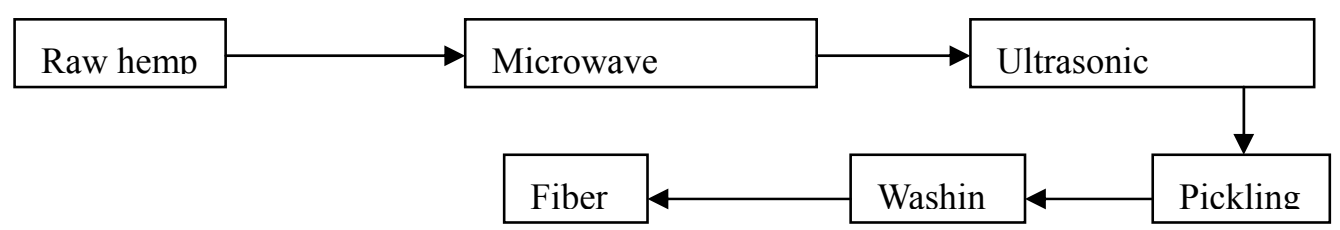

* Microwave treatment: $0.5 \% \mathrm{NaoH}$; ultrasonic treatment: $28 \mathrm{KHz}, 0 \sim 3.0 \% \mathrm{NaoH}, 45 \sim 60{ }^{\circ} \mathrm{C}$; pickling: $2 \mathrm{~g} / \mathrm{LH}_{2} \mathrm{SO}_{4}$; washing: water $>70^{\circ} \mathrm{C}$.

Figure 1. Ultrasonic degumming technology

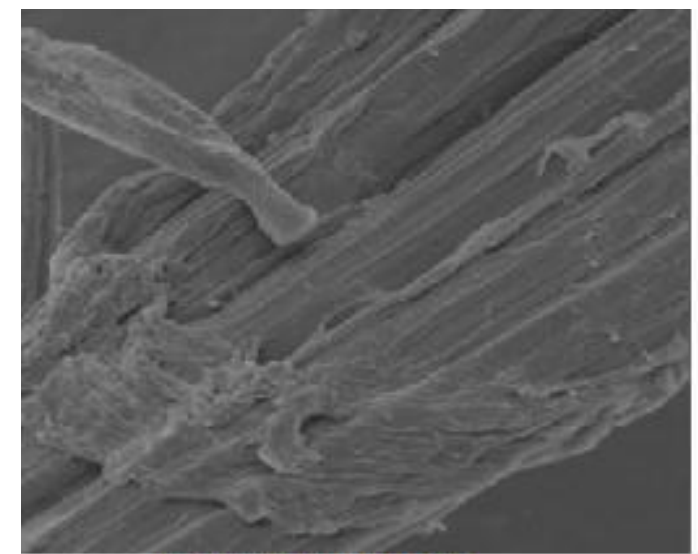

hemp after pretreating

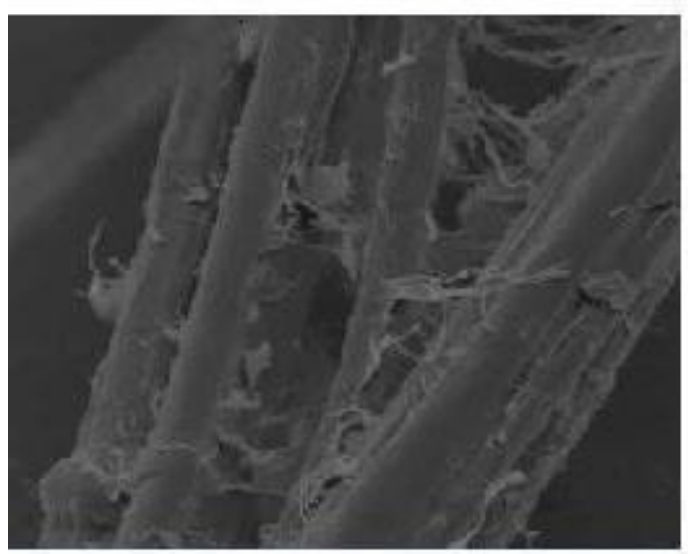

Intermediate

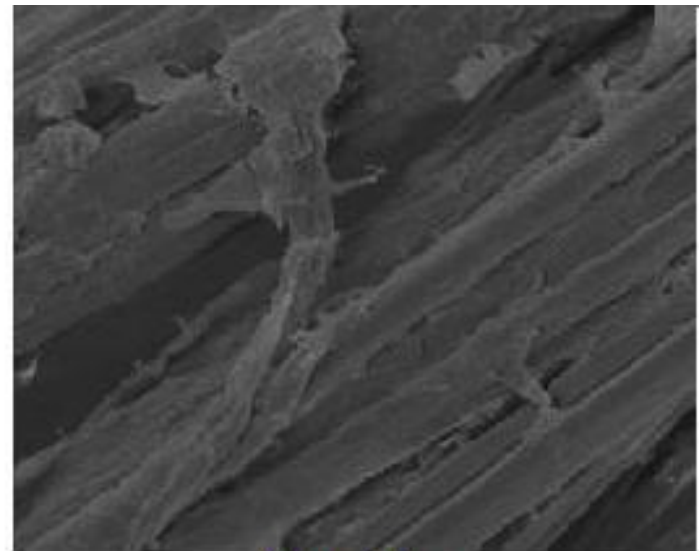

Intermediate

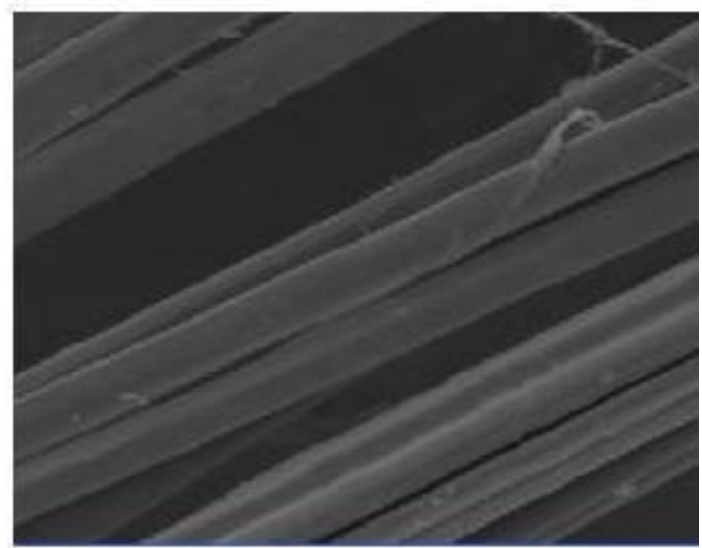

$28 \mathrm{KHz}, 0.45 \mathrm{~W} / \mathrm{cm} 2,1.5 \% \mathrm{NaoH}, 55^{\circ} \mathrm{C}$

Figure 2. The electronic microscope photograph of different treat extent 


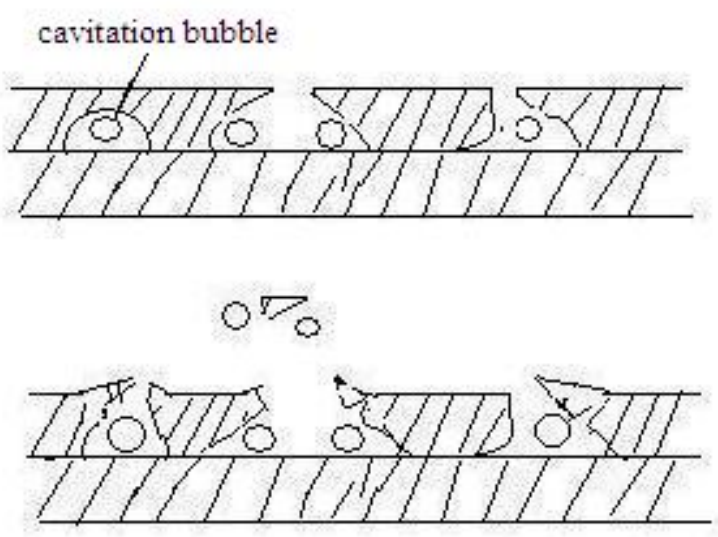

Figure 3. Cavitations peel off gum by cavitations

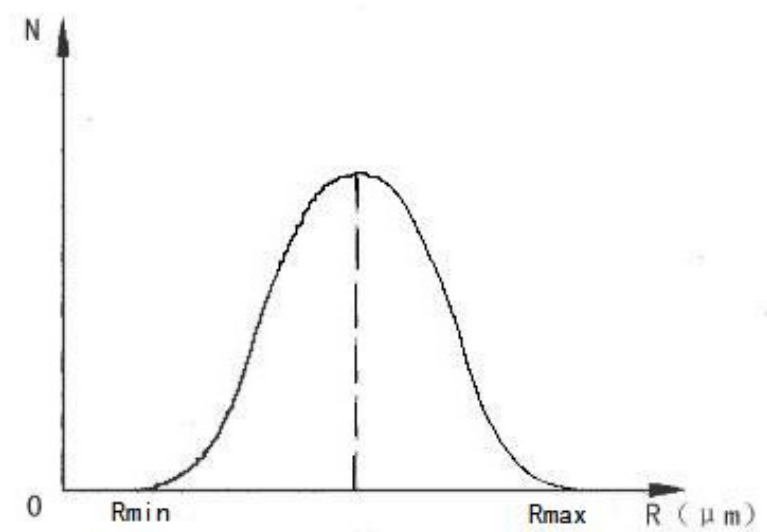

Figure 4. Gaussian distribution of radius of cavitations bubble 